OPEN ACCESS

Edited by:

Chi Keung Lau,

Teesside University, United Kingdom

Reviewed by:

Yiwen Zhang,

Anhui University, China

Weilin Xiao,

Zhejiang University, China

${ }^{*}$ Correspondence:

Wei-Bai Liu

weibai.liu1972@yahoo.com

Specialty section

This article was submitted to

Environmental Psychology,

a section of the journal

Frontiers in Psychology

Received: 28 March 2021

Accepted: 06 April 2021

Published: 28 May 2021

Citation:

Song K, Liu W-B, Qing Y, Tian M-N

and Pan W-T (2021) Efficiency

Analysis of New Rural Cooperative

Medical System in China: Implications

for the COVID-19 Era.

Front. Psychol. 12:686954

doi: 10.3389/fpsyg.2021.686954

\section{Efficiency Analysis of New Rural Cooperative Medical System in China: Implications for the COVID-19 Era}

\author{
Ke Song ${ }^{1}$, Wei-Bai Liu ${ }^{1 *}$, Yan Qing ${ }^{1}$, Meng-Nan Tian ${ }^{2}$ and Wen-Tsao Pan ${ }^{1}$ \\ ${ }^{1}$ School of Economics and Management, Hunan University of Science and Engineering, Yongzhou, China, ${ }^{2}$ School of \\ Foreign Languages, Hunan University of Science and Engineering, Yongzhou, China
}

The sudden outbreak of coronavirus disease 2019 (COVID-19) has caused a huge impact on the Chinese residents' health and economic level. In the pandemic background, the country and its institutions have introduced pandemic-related insurance to stabilize the national situation. At this stage, insurance has played an increasingly important role in social life. With the popularization of insurance, the idea of buying insurance to avoid risk has gradually become popular among people. Among them, the New Rural Cooperative Medical System (NRCMS) has been farmers' common choice. The NRCMS, a mutual aid system created by farmers spontaneously in the country, plays a great role in guaranteeing farmers access to basic health services, alleviating poverty caused by disease and returning to poverty due to disease, and promoting poverty alleviation and rural revitalization. Given this backdrop, we study the efficiency of the NRCMS that can effectively promote poverty alleviation and rural revitalization and ensure the people's happy life. Implementing the Data Envelopment Analysis (DEA), we find that technological progress is one of the main factors influencing the efficiency of the NRCMS. Therefore, it is important to improve the technology for providing the efficiency of the NRCMS and promoting the happiness of the society.

\footnotetext{
Keywords: two-stage network idea, DEA-Malmquist, New Rural Cooperative Medical System, COVID-19 pandemic, efficiency
}

\section{INTRODUCTION}

Coronavirus disease 2019 (COVID-19) continues to appear in many countries, which has brought many bad effects to the country and society. As of March 31,2021, the number of infected people globally is almost 130 million, and the number of cases is increasing by more than 600,000 every day. The spread of infection affects all countries and regions worldwide and has caused more than 2.8 million deaths worldwide (Dong et al., 2020). This outbreak has infected a large number of people. The pandemic, which has infected so many people and spread so fast, is the most serious infectious disease disaster human society has experienced in nearly 100 years. Now, the global COVID-19 pandemic has not been effectively contained, and many European countries are beginning to experience a third-wave of the pandemic. However, if the global scientific and medical fields spare no effort to combat the pandemic, the future of the pandemic is uncertain. However, governments' policy and trust in these policies are central to combat the pandemic (Gozgor, 2021). 
At this stage, we need to deeply analyze the impact of COVID-19 on the country and society, improve the longterm mechanism for global public security, improve the global governance system, and accelerate a community building with a shared future humankind. Under the pandemic situation, the New Rural Cooperative Medical System (NRCMS) has also played a certain role. The NRCMS was formally proposed by the Chinese government in October 2002 to actively guide farmers to establish a new type of rural cooperative medical insurance based on overall planning for serious diseases. In 2009, the NRCMS was established for the status of the rural basic medical security system. Until now, the NRCMS in the country has experienced a leap-forward development, reduced a lot of burden to farmers, and at the same time given a certain security. Many scholars study the effect of new farming in succession, and the corresponding research is as follows below.

For instance, Zhao and Gan (2019) proposed that the NRCMS improves the rate of rural residents receiving medical treatment, plays a significant role in reducing residents' medical expenditure, alleviates the acceptance pressure of municipal hospitals, guides rural residents to seek medical treatment nearby, and improves the utilization rate of medical services. Wang et al. (2009) proposed that participating in the NRCMS can effectively improve rural residents' medical services. Guo (2020) showed that under different risk preferences, farmers' participation in the NRCMS would also change and analyzed the influence of subjective and objective risk preferences on their insurance behavior. Guo et al. (2013) used the gray correlation analysis method to get the gray correlation order of the influencing factors of the NRCMS. The NRCMS should be designed and improved to adapt to objective conditions to achieve sustainable development. Cui et al. (2021) studied the province's livability level measurement based on the twostage Data Envelopment Analysis (DEA) model. The authors comprehensively evaluated the livability level of the province from seven aspects. Xiao and Yang (2020) evaluated listed companies' innovation efficiency in China's wine industry based on a two-stage network DEA. They concluded that there were great differences in the innovation efficiency among listed companies in China's wine industry. There was an imbalance in the input and output of the technology development stage in innovation activities. Wang (2020) concluded that the new energy industry's overall financing efficiency was relatively low by constructing a two-stage chain network DEA model. Chen and Guan (2021) concluded that the allocation efficiency of health resources in traditional Chinese medicine (TCM) hospitals in China was poor using the DEA-Malmquist index. Jin et al. (2021) carried out static and dynamic analyses on the efficiency of inclusive digital finance regulating urban and rural residents' welfare differential in 31 provinces of China based on the DEAMalmquist-Tobit model. The authors provided the main factors affecting inclusive digital finance's efficiency regulating urban and rural residents' welfare differential. Yang et al. (2021) studied county-level public hospitals' operational efficiency in Hainan Province based on the DEA-Malmquist model. The authors proposed the need to raise the technical efficiency and the scale efficiency.
In conclusion, the NRCMS has played an important role in recent years. Further exploration of the efficiency of the NRCMS can help better implement the NRCMS policies. In this paper, the two-stage network DEA and the DEA-Malmquist are used to study the efficiency of the NRCMS. There are few research studies on the NRCMS by this method in China, which helps explore the key influencing stages of the NRCMS to determine the important influencing factors. We enhance the previous papers by using new methods and provide some implications on the COVID-19 era.

The rest of the paper is organized as follows. The Methodology section explains the methodologies used in the paper. The Empirical Analysis section provides the details of the empirical analyses. The Conclusion section concludes.

\section{METHODOLOGY}

\section{Two-Stage Network DEA}

The specific model of the two-stage network DEA is constructed as follows: suppose there are many influencing factors, and each influencing factor has $n$ inputs, $m$ outputs, and $g$ intermediate outputs, where $\mathrm{Xi}$ is the input of the first-stage fundraising system of the $\mathrm{i}$-th influencing factor $(\mathrm{DMU}), \mathrm{Xi}=(\mathrm{xi} 1, \mathrm{xi} 2 \ldots, \mathrm{xin})^{\mathrm{T}}$; Yi is the output of the first-stage fundraising system and the input of the second-stage fund allocation system of the i-th decision unit, $\mathrm{Yi}=(\mathrm{Yi} 1, \mathrm{Yi} 2 \ldots \mathrm{Yig})^{\mathrm{T}}$; $\mathrm{Zi}$ is the output of the fund allocation system in the second stage, $\mathrm{ZI}=(\mathrm{ZI} 1, \mathrm{ZI} 2 \ldots \mathrm{ZIN})$; and $\mathrm{O}=$ $(\mathrm{O} 1, \mathrm{O} 2 \ldots, \mathrm{ON}), \mathrm{P}=(\mathrm{P} 1, \mathrm{WP} 2 \ldots, \mathrm{pg}), \mathrm{Q}=(\mathrm{q} 1, \mathrm{q} 2 \ldots, \mathrm{qm})$, respectively, represent the weights of input, intermediate, and output variables.

$$
\left\{\begin{array}{l}
\mathrm{OTx}_{0}=1 \\
\mathrm{QTYi}-\mathrm{O}^{\mathrm{T}} \mathrm{Xi} \leq 0 \\
\text { s. t. } \mathrm{PTYi}-\mathrm{O}^{\mathrm{T}} \mathrm{Xi} \leq 0 \\
\mathrm{QTZi}-\mathrm{P}^{\mathrm{T}} \mathrm{Yi} \leq 0 \\
\mathrm{Q} \geq \varepsilon \mathrm{em}, \mathrm{O} \geq \varepsilon \mathrm{ep}, \mathrm{P} \geq \varepsilon \text { eg }
\end{array}\right.
$$

Where $\varepsilon$ is a non-Archimedes infinitesimal quantity, e $\mathrm{T}=(1$, $1 \ldots 1)$. If $\mathrm{O}^{*}, \mathrm{P}^{*}$, and $\mathrm{Q}^{*}$ are the optimal solution of the model, then the efficiency of DMU whole process and sub-process is $\mathrm{E}_{0}$ $=\mathrm{Q}^{* \mathrm{~T}} \mathrm{Z}_{0} \mathrm{O}^{* \mathrm{~T}} \mathrm{X}_{0}, \mathrm{E} 1=\mathrm{Q}^{*}{ }^{\mathrm{T}} \mathrm{Z}_{0} / \mathrm{O}^{* \mathrm{~T}} \mathrm{Y}_{0}, \mathrm{E} 2=\mathrm{Q}^{* \mathrm{~T}} \mathrm{Z}_{0} / \mathrm{O}^{* \mathrm{~T}} \mathrm{Y}_{0}$, where $\mathrm{E}_{0}$ is the whole stage, E1 and E2 are the first and second stages, respectively, and $\mathrm{E}_{0}=\mathrm{E} 1 \times \mathrm{E} 2$.

\section{DEA-Malmquist Method}

Fare et al. (1994) combined a nonlinear programming method of the Malmquist index theory with the DEA method theory, making the Malmquist index widely applied in the empirical literature. This method has been widely applied to measure production efficiency in finance, industry, medical treatment, and other sectors, and international comparative studies have been conducted based on efficiency measurement results. The specific formula is as follows:

suppose (xt,yt) represents the input and output of the $t$ period, $(x t+1, y t+1)$ represents the input and output of the $t+1$ period, and $\mathrm{D}_{0}(\mathrm{xt}+1, \mathrm{yt}+1) / \mathrm{D}_{0}(\mathrm{xt}, \mathrm{yt})$ represents the change 
of technical efficiency from $t$ period to $t+1$ period under the technical conditions of the $\mathrm{t}$ period; $\mathrm{D}_{0} \mathrm{~T}+1(\mathrm{X} \mathrm{T}+1, \mathrm{Y} \mathrm{T}$ $\left.+1) / \mathrm{D}_{0} \mathrm{~T}+1(\mathrm{X} \mathrm{T}, \mathrm{Y} T)\right]^{1 / 2}$ represents the change in technical efficiency from $\mathrm{T}$ to $\mathrm{T}+1$ under the technical conditions of $\mathrm{T}+$ 1 , where the subscript 0 represents the constant return to scale. The following formula can express the Malmquist index:

$$
\begin{aligned}
& M_{0}\left(x^{t}, y^{t}, x^{t+1}, y^{t+1}\right)=\left[D_{0}\left(x^{t+1}, y^{t+1}\right) / D_{0}\left(x^{t}, y^{t}\right)\right. \\
& \left.\times D_{0}^{t+1}\left(x^{t+1}, y^{t+1}\right) / D_{0}{ }^{t+1}\left(x^{t}, y^{t}\right)\right]^{1 / 2}
\end{aligned}
$$

At the same time, the Malmquist approach can be divided into two parts: technical efficiency and change. The specific formula is as follows:

$$
\begin{aligned}
& \text { Technical efficiency EC }=\mathrm{D}_{0} \mathrm{~T}+1\left(\mathrm{X}_{0} \mathrm{~T}+1, \mathrm{Y}_{0} \mathrm{~T}+1\right) \\
& / \mathrm{D}_{0}\left(\mathrm{X}_{0} \mathrm{~T}, \mathrm{Y}_{0} \mathrm{~T}\right) \\
& \text { Technical change } \mathrm{Tc}=\left[\mathrm{D}_{0} \mathrm{t}\left(\mathrm{x}_{0} \mathrm{t}+1, \mathrm{y}_{0} \mathrm{t}+1\right)\right. \\
& / \mathrm{D}_{0}\left(\mathrm{x}_{0} \mathrm{t}+1, \mathrm{y}_{0} \mathrm{t}+1\right) \times \mathrm{D}_{0} \mathrm{t}+1\left(\mathrm{x}_{0} \mathrm{t}+1, \mathrm{y}_{0} \mathrm{t}+1\right) \\
& \left./ \mathrm{D}_{0} \mathrm{t}+1\left(\mathrm{x}_{0} \mathrm{t}, \mathrm{y}_{0} \mathrm{t}\right)\right] \\
& \mathrm{M}=\mathrm{EC} * \mathrm{TC}
\end{aligned}
$$

EC mainly refers to the utilization of existing technology by decision-making units if EC $>1$ means that the efficiency of the main body of production is improved, resources are fully utilized, and management level is improved. On the contrary, if $\mathrm{EC}<1$, resources are not fully utilized, main body efficiency is poor, and management level needs to be strengthened. TC mainly reflects the technological progress on the decisionmaking unit if Tc $>1$ indicates technological progress. Tc $<1$ indicates no technological progress or regression, and continuous improvement of the technology is needed. Tc $=1$ indicates no technological progress.

\section{EMPIRICAL ANALYSIS}

\section{Sample Description}

In this paper, the data are selected from the year between 2004 and 2014 , the $\times 1$ [the new rural cooperative medical county (area and city)], $\times 2$ (to participate in the new rural cooperative medical number), $\times 3$ (the new rural cooperative medical service rate), $\times 4$ (the new rural cooperative medical fund spending), $\times 5$ (the total amount of the new rural cooperative medical financing this year), and $\times 6$ (the new rural cooperative medical compensation benefit passengers). The data are obtained from the Chinese Longitudinal Healthy Longevity Survey (CLHLS) of Zeng et al. (2017). The descriptive statistics of raw dataset is reported in Table 1.

\section{Results of the Two-Stage Network DEA Method}

The results of the two-stage network DEA method are provided in Table 3.

It can be seen from Table 3 that the overall efficiency of the second stage is higher than that of the first stage; there are 3 years with an efficiency value of 1 in the second stage, and only one year with an efficiency value of 1 in the first stage; the efficiency value of the second stage from 2009 to 2014 is generally high. Therefore, the first stage mainly affects the overall efficiency; in the year 2005, 2006, 2008, and other years, the efficiency of the first stage is poor, but the efficiency of the second stage is efficient, indicating that there may be technological progress in the second stage compared with the first stage.

\section{Results of the DEA-Malmquist Method}

The results of the DEA-Malmquist method are provided in

\begin{tabular}{|c|c|c|c|c|c|c|}
\hline Time & $\begin{array}{c}\mathrm{X} 1 \\
\text { (PCS) }\end{array}$ & $\begin{array}{c}\text { X2 } \\
\text { (million people) }\end{array}$ & $\begin{array}{l}\text { X3 } \\
(\%)\end{array}$ & $\begin{array}{c}\text { X4 } \\
\text { (million yuan) }\end{array}$ & $\begin{array}{c}\mathrm{X} 5 \\
\text { (million yuan) }\end{array}$ & $\begin{array}{c}\text { X6 } \\
\text { (million people) }\end{array}$ \\
\hline 2014 & 2,349 & 7.36 & 98.9 & $2,890.4$ & $3,025.28$ & 16.52 \\
\hline 2013 & 2,489 & 8.02 & 99 & 2,908 & $2,972.48$ & 19.42 \\
\hline 2012 & 2,566 & 8.05 & 98.3 & 2,408 & $2,484.7$ & 17.45 \\
\hline 2011 & 2,637 & 8.32 & 97.5 & $1,710.19$ & $2,047.56$ & 13.15 \\
\hline 2010 & 2,678 & 8.36 & 96 & $1,187.8$ & 1,308.33 & 10.87 \\
\hline 2009 & 2,716 & 8.33 & 94.2 & 922.9 & 944.4 & 7.59 \\
\hline 2008 & 2,729 & 8.15 & 91.5 & 662.3 & 784.58 & 5.85 \\
\hline 2007 & 2,451 & 7.26 & 86.2 & 346.63 & 427.97 & 4.53 \\
\hline 2006 & 1,451 & 4.1 & 80.7 & 155.8 & 213.59 & 2.72 \\
\hline 2005 & 678 & 1.79 & 75.7 & 61.75 & 75.35 & 1.22 \\
\hline 2004 & 333 & 0.8 & 75.2 & 26.37 & 40.29 & 0.76 \\
\hline
\end{tabular}
Table 4.

As shown in Table 4, every year, the EC, PEC, and SEC's efficiency values are obtained as one. This evidence indicates an efficient situation. In addition, the efficiency value of the TC was not up to 1 every year. This case is a situation where there is no progress or deterioration in the technology. Still, with the

TABLE 1 | Descriptive statistics of raw dataset.

The input/output/intermediate variables of the two-stage network DEA are provided in Table 2. The input/output variables of DEA-Malmquist are also reported in Table 2. 
TABLE 2 | Variables in the two-stage network DEA.

\begin{tabular}{|c|c|c|c|}
\hline Input/output & Names of index & Index tag & Units \\
\hline \multirow[t]{4}{*}{ Input } & $\begin{array}{l}\text { Counties (districts and county-level cities) carrying out the new rural cooperative } \\
\text { medical care system }\end{array}$ & $\mathrm{X} 1$ & Pcs \\
\hline & Number of people participating in the new rural cooperative medical care system & $\mathrm{X} 2$ & Million people \\
\hline & Expenditures for the new rural cooperative medical care system & X4 & Million yuan \\
\hline & New rural cooperative medical system this year total financing & X5 & Million yuan \\
\hline Intermediate & Participation rate of the new rural cooperative medical care system & X3 & $\%$ \\
\hline Output & The number of beneficiaries of the new rural cooperative medical care system & X6 & Million people \\
\hline \multicolumn{4}{|c|}{ Variables in the DEA-Malmquist Method } \\
\hline \multirow[t]{4}{*}{ Input } & $\begin{array}{l}\text { Counties (districts and county-level cities) carrying out the new rural cooperative } \\
\text { medical care system }\end{array}$ & $\mathrm{X} 1$ & Pcs \\
\hline & Number of people participating in the new rural cooperative medical care system & $\mathrm{X} 2$ & Million people \\
\hline & Expenditures for the new rural cooperative medical care system & X4 & Million yuan \\
\hline & New rural cooperative medical system this year total financing & X5 & Million yuan \\
\hline \multirow[t]{2}{*}{ Output } & Participation rate of the new rural cooperative medical care system & X3 & $\%$ \\
\hline & The number of beneficiaries of the new rural cooperative medical care system & X6 & Million people \\
\hline
\end{tabular}

increase of time, the efficiency value of the TC closer to 1 shows that the technology is improving year by year, but the efficiency value is no more than 1 . Therefore, the most important reason why the $M$-value is $<1$ is that the TC value is $<1$. In terms of the ranking of the $M$-value, the top 5 years were 2010-2014, among which 2011 ranked first and 2010 ranked as the fifth.

\section{CONCLUSION}

Our empirical analyses in this paper show that the first stage's efficiency is poor, the second stage's efficiency is efficient, and the overall efficiency is poor. Therefore, the first stage is the stage that mainly affects the overall efficiency. We suggest that the second stage is more efficient than the first stage for the following reasons. In 2009, the new agricultural cooperation was established as the basic medical security in rural areas. Then, from 2010 to 2014, relevant documents and policies were issued every year. For example, in 2010, the Eleventh Five-Year Plan Conference was held, requiring the NRCMS to cover more than $80 \%$ of rural areas by 2010 . In 2011 , the medical and health system's five key reforms were promulgated, which raised the standard of medical insurance subsidy from 120 to $200 \mathrm{RMB}$ per person. Since then, the cost of medical insurance subsidies has been increasing continuously every year. In 2014, the Notice on Raising the 2014 Funding Standards for the New Rural Cooperative Medical Care and the Basic Medical Insurance for Urban Residents was issued. The subsidy for medical insurance was raised to $320 \mathrm{RMB}$ per person, increasing $40 \mathrm{RMB}$ than the subsidy in 2013. These subsidies are significantly increasing in the COVID-19 era, and it enhances the happiness and life satisfaction of the Chinese farmers. However, China's medical insurance funding level, especially basic medical insurance for rural and non-working urban residents, is still low. For example, vaccines are not included in the medical insurance coverage, and public health funds paid vaccinations.
TABLE 3 | Results of the two-stage network DEA method.

\begin{tabular}{lcccc}
\hline No & Node & DMU & Score & Ranking \\
\hline 1 & 1 & 2004 & 1 & 1 \\
2 & 1 & 2005 & 0.494416 & 13 \\
3 & 1 & 2006 & 0.246282 & 20 \\
4 & 1 & 2007 & 0.242821 & 21 \\
5 & 1 & 2008 & 0.281633 & 17 \\
6 & 1 & 2009 & 0.235476 & 22 \\
7 & 1 & 2010 & 0.342022 & 15 \\
8 & 1 & 2011 & 0.371864 & 14 \\
9 & 1 & 2012 & 0.265954 & 19 \\
10 & 1 & 2013 & 0.305135 & 16 \\
11 & 1 & 2014 & 0.27504 & 18 \\
12 & 2 & 2004 & 1 & 1 \\
13 & 2 & 2005 & 1 & 1 \\
14 & 2 & 2006 & 1 & 1 \\
15 & 2 & 2007 & 0.831183 & 6 \\
16 & 2 & 2008 & 0.585505 & 12 \\
17 & 2 & 2009 & 0.759278 & 9 \\
18 & 2 & 2010 & 0.784924 & 8 \\
19 & 2 & 2011 & 0.642427 & 11 \\
20 & 2 & 2012 & 0.845297 & 5 \\
21 & 2 & 2013 & 0.786354 & 7 \\
22 & 2 & 2014 & 0.657252 & 10 \\
\hline & & & &
\end{tabular}

To sum up, due to the implementation of relevant policies and each subsidy fee adjustment that is more in line with the national conditions, the NRCMS gradually develops well. In 2008, the overall efficiency and the first-stage efficiency were poor, but the second stage efficiency is better. This evidence means that the second stage is a technological improvement over the first stage. Technological progress is the main reason that affects the 
TABLE 4 | Results of the DEA-Malmquist method.

\begin{tabular}{|c|c|c|c|c|c|c|c|}
\hline Time & Stage & EC & TC & PEC & SEC & Number of $\mathbf{M}$ & Ranking \\
\hline 2005 & A & 1 & 0.607443 & 1 & 1 & 0.607443 & 9 \\
\hline 2006 & A & 1 & 0.62593 & 1 & 1 & 0.62593 & 8 \\
\hline 2007 & A & 1 & 0.688009 & 1 & 1 & 0.688009 & 7 \\
\hline 2008 & A & 1 & 0.802715 & 1 & 1 & 0.802715 & 6 \\
\hline 2009 & A & 1 & 0.981397 & 1 & 1 & 0.981397 & 2 \\
\hline 2010 & B & 1 & 0.892905 & 1 & 1 & 0.892905 & 5 \\
\hline 2011 & B & 1 & 0.990985 & 1 & 1 & 0.990985 & 1 \\
\hline 2012 & B & 1 & 0.97817 & 1 & 1 & 0.978171 & 3 \\
\hline 2013 & B & 1 & 0.953863 & 1 & 1 & 0.953863 & 4 \\
\hline
\end{tabular}

$M$-value, which is related to some less mature technologies of the NRCMS.

There are several implications, especially for the COVID19 era. First, the procedures for participating in and applying for reimbursement for the NRCMS are tedious, and farmers are worried that the policy will change every year and not get adequate protection. Second, unable to cross area to hand in, new agriculture closes to want to attend domicile ground, cannot be in residence place to hand in, and protect personnel from ginning to bring certain not convenient. Third, it is inconvenient to reimburse other places, and the payment channel is single. It can only be reimbursed in the place of residence, and the round-trip fare is not necessarily cost-effective. Fourth, with the growth of years, technology keeps developing, but the efficiency value has not exceeded. Therefore, technology needs to be further improved, such as developing corresponding software to simplify the cumbersome insurance reimbursement procedures. In this software, one can see the payment cost and time of different places. One can also make payment and settlement in the corresponding software to get the corresponding guarantee regardless of where you live or in other places. In this way, the NRCMS will develop better and better and better guarantee farmers out of poverty and promote rural revitalization. The outbreak of the pandemic has also aroused people's deep thinking about rural medical treatment. The pandemic prevention and control in rural areas face great challenges because of the relatively weak medical and health conditions, the large number of people going out and returning home, and the large mobility.

\section{REFERENCES}

Chen, Y., and Guan, C.-L. (2021). Study on health resource allocation efficiency of TCM hospitals in China based on DEA-Malmquist Index. Mod. Hosp. Manag. 19, 17-20. doi: 10.3969/j.issn.1672-4232.2021. 01.005

Cui, Y., Zhu, W. W., and Gan, G. S. (2021). Research on the measurement method of provincial livability level based on two-stage network DEA model. Ecol. Econ. $37,82-87$.

Dong, E., Du, H., and Gardner, L. (2020). An interactive web-based dashboard to track COVID-19 in real time. Lancet Infect. Dis. 20, 533-534. doi: 10.1016/S1473-3099(20)30120-1
It is necessary to implement relevant policies of the NRCMS by combining the pandemic situation so that farmers can have insurance to rely on, and the NRCMS can play an important role during the pandemic period to strengthen the prevention and control in rural areas.

\section{DATA AVAILABILITY STATEMENT}

Publicly available datasets were analyzed in this study. This data can be found here: The data are obtained from the Chinese Longitudinal Healthy Longevity Survey (CLHLS) of Zeng et al. (2017): https://www.icpsr.umich.edu/web/ICPSR/studies/36692.

\section{AUTHOR CONTRIBUTIONS}

KS: implementing empirical analyses. W-BL: writing the manuscript. YQ: data collection and methodology. M-NT: reviewing the manuscript. W-TP: funding access. All authors contributed to the article and approved the submitted version.

\section{FUNDING}

This research was funded by the Scientific Research Project of the Education Department of Hunan Province (Project \#: 20C0840), the Outstanding Youth Project of the Natural Science Foundation of Hunan Province (Project \#: 2019JJ20009), and the Hunan Philosophy and Social Science Foundation Project (Project \#: 20YBA121). 
Jin, F., Huang, J., and Wu, Q.-T. (2021). Research on the Efficiency and Influencing Factors of Digital Inclusive Finance in the Adjustment of Urban and Rural Residents' Welfare Disparities: Based on DEA-Malmquist-Tobit model. Finan. Theory Pract. 3, 14-22.

Wang, H.-R. (2020). Research on Financing Efficiency Evaluation of New Energy Industry Based on Two-stage Chain Network DEA Model. Green Account. 6, 16-20. doi: 10.14153/j.cnki.lsck.2020.06.005

Wang, Y.-Q., Zang, B., and Lv, M. Y. (2009). An empirical analysis of the factors influencing the utilization of medical services for rural residents: a case study of five counties in northern Jiangsu. Jiangsu Soc. Sci. 2, 227-232. doi: 10.13858/j.cnki.cn32-1312/c.2009.02.024

Xiao, J.-L., and Yang, C.-J. (2020). Evaluation of innovation efficiency of listed companies in China's wine industry - a study based on two-stage network DEA. Oper. Manag. 11, 48-53. doi: 10.16517/j.cnki.cn12-1034/f.2020.11.010

Yang, Y., Liu, J., and Xue, W.-J. (2021). Analysis of operation efficiency and influencing factors of county-level Public Hospitals in Hainan Province based on DEA-Malmquist model. Soft Sci. Health 35, $62-65$.
Zeng, Y., Vaupel, J., Xiao, Z., Liu, Y., and Zhang, C. (2017). Chinese Longitudinal Healthy Longevity Survey (CLHLS), 1998-2014. Inter-university Consortium for Political and Social Research.

Zhao, Y.-M., and Gan, Y. (2019). Effect evaluation of New Rural Cooperative Medical Care on medical expenditure of rural residents. Chin. J. Soc. Med. 36, 411-415. doi: 10.35646/kodisa.icbe.2019.7.5.411

Conflict of Interest: The authors declare that the research was conducted in the absence of any commercial or financial relationships that could be construed as a potential conflict of interest.

Copyright (C) 2021 Song, Liu, Qing, Tian and Pan. This is an open-access article distributed under the terms of the Creative Commons Attribution License (CC BY). The use, distribution or reproduction in other forums is permitted, provided the original author(s) and the copyright owner(s) are credited and that the original publication in this journal is cited, in accordance with accepted academic practice. No use, distribution or reproduction is permitted which does not comply with these terms. 